\title{
Representações sociais sobre saúde e meio ambiente para equipes de Estratégia Saúde da Família
}

\section{Social representations on health and environment for the Family Health Strategy teams}

\author{
Gisele Loise Dias \\ Universidade Federal de Santa Maria. Departamento de \\ Enfermagem. Santa Maria, RS, Brasil. \\ E-mail: gidiasıฉ®gmail.com
}

\section{Silviamar Camponogara}

Universidade Federal de Santa Maria. Departamento de Enfermagem. Santa Maria, RS, Brasil.

E-mail: silviaufsmळyahoo.com.br

\section{Valdecir Zavarese da Costa}

Universidade Federal de Santa Maria. Departamento de Enfermagem. Santa Maria, RS, Brasil.

E-mail: valdecircosta2005ळyahoo.com.br

\section{Marta Regina Cezar-Vaz}

Universidade Federal de Santa Maria. Departamento de Enfermagem. Santa Maria, RS, Brasil.

E-mail: cezarvazœvetorial.net

\section{Teresinha Heck Weiller}

Universidade Federal de Santa Maria. Departamento de Enfermagem. Santa Maria, RS, Brasil.

E-mail: weiller2ळhotmail.com

\section{Leticia Silveira Cardoso}

Universidade Federal do Pampa. Departamento de Enfermagem. Uruguaiana, RS, Brasil.

E-mail: Isc_enfळyahoo.com.br

\section{Correspondência}

Gisele Loise Dias

Av. Roraiama, 1.000, prédio 26, sala 1.302, Santa Maria, RS, Brasil. CEP $97105-900$.

Resumo

Atualmente, sabe-se que as questões que envolvem a saúde possuem uma relação com diversos determinantes, dentre os quais, o meio ambiente merece destaque especial. Nesse sentido, a relação saúde e meio ambiente é um importante aspecto a ser considerado, particularmente nas práticas de trabalhadores das equipes de Estratégias Saúde da Família (ESF). 0 objetivo deste estudo é conhecer as representações sociais sobre saúde e meio ambiente para equipes de Estratégia Saúde da Família. É um estudo qualitativo, descritivo-exploratório, baseado na teoria das representações sociais. Os dados foram coletados entre fevereiro e junho de 2016, em um município localizado no interior do Rio Grande do Sul, por meio de pesquisa documental e entrevista semiestruturada. Participaram deste estudo 19 trabalhadores de ESF. Os dados foram analisados conforme análise de conteúdo temática, buscandose o núcleo central da representação social e os elementos periféricos. A partir da análise dos dados delineou-se a seguinte representação: a salubridade do território. Os elementos periféricos relacionados à representação são: água, resíduos sólidos urbanos e agrotóxicos e poluição atmosférica. Conclui-se que a compreensão da relação saúde e meio ambiente está intrinsecamente relacionada com os danos que o meio ambiente pode causar na saúde.

Palavras-chave: Saúde da Família; Profissionais de Saúde; Meio Ambiente; Saúde; Representações Sociais; Psicologia Social. 


\section{Introdução}

Currently, it is well known that issues involving health are related to several determinants, among which the environment should be highlighted. In this sense, the relation between health and environment is an important aspect to be considered, especially in the practices of workers within the Family Health Strategy (FHS) teams. The objective of this study was to know the social representations about health and environment for Family Health Strategy teams. This is a qualitative, descriptive-exploratory study, based on the social representations theory. Data were collected from February to June 2016, in a municipality located in the countryside of Rio Grande do Sul State, through documentary research and semi-structured interviews. Overall, 19 Family Health Strategy workers participated in this study. The data were analyzed according to thematic content analysis, seeking the central nucleus of social representation and the peripheral elements. From the analysis of the data the following representation was outlined: The salubrity of the territory. The peripheral elements related with representation are: water, municipal solid waste, and agrochemicals and atmospheric pollution. We concluded that the understanding of the relationship between health and environment is intrinsically related to the damages the environment can bring to health.

Keywords: Family Health Strategy; Health Professionals; Environment; Health; Social Representations; Social Psychology.
As questões envolvendo a relação entre saúde e meio ambiente vêm ganhando espaço a nível mundial, principalmente após a década 1970 (Rangel et al., 2015). O tema saúde e meio ambiente abrange tanto questões que possuem dimensões globais, como o aquecimento global e a camada de ozônio, como questões locais, que atingem diretamente grupos populacionais, por meio de problemas como o desmatamento e a ausência de esgotamento sanitário, os quais podem afetar a saúde da população (Frumkin, 2016).

De acordo com a Organização Mundial da Saúde, em 2012, do total de óbitos no mundo, 23\% foram atribuíveis às causas ambientais. Esse valor representa, aproximadamente, 12,6 milhões dos óbitos ocorridos naquele ano. Dentre essas causas, destacam-se tanto as catástrofes climáticas como as relacionadas à ausência de acesso aos serviços de saneamento básico e alimentação adequada (WHO, 2016).

Em face desses dados, percebe-se que a abordagem do tema tem se constituído em uma necessidade premente em diversas áreas, inclusive no campo da saúde. Contudo, destaca-se que a temática demanda a necessidade de um olhar para além do modelo tradicional de saúde, do tratamento do doente, em prol da melhoria da saúde da população, reconhecendo e identificando o ambiente como um dos fatores que influenciam a saúde (Rangel et al, 2015). A Estratégia Saúde da Família (ESF) destaca-se como a principal estratégia governamental para incorporar essa discussão tendo em vista que se busca a reorientação do modelo de atenção, com vistas a uma nova organização dos serviços, que tem como premissas o vínculo, a humanização no acolhimento e a articulação com outras instituições e setores (Shimizu; Reis, 2011). Portanto, espera-se a reorientação do processo de trabalho com aprofundamento dos princípios, diretrizes e fundamentos da Atenção Primária à Saúde (APS) e, ainda, ampliação da resolutividade no campo da saúde (Brasil, 2012).

Contudo, questiona-se como esse tema vem sendo abordado - o âmbito da ESF -, tendo em vista que essa discussão ainda é recente e as práticas assistenciais, em muitos locais, ainda permanecem aderidas ao modelo tradicional. Portanto, entende-se que a compreensão das relações entre ambiente e saúde é 
um desafio, considerando que a vulnerabilidade às doenças, a exposição ambiental e seus efeitos sobre a saúde distribuem-se de maneira diferente segundo os indivíduos, regiões e grupos sociais e relacionamse com a pobreza, as crises econômicas e o nível educacional (Rangel et al., 2015).

No Brasil, a relação saúde e meio ambiente foi legitimada a partir da promulgação da Lei $\mathrm{n}^{0}$ 8080/1990, que define os determinantes e os condicionantes em saúde como: alimentação, moradia, saneamento básico, meio ambiente, trabalho, renda, educação, atividade física, transporte, lazer e acesso aos bens e serviços essenciais (Brasil, 2013). Assim, ocorre a ampliação do conceito saúde e doença, uma vez que se reconhece que a perturbação e o esgotamento dos recursos naturais, incluindo as alterações climáticas, têm implicações profundas no modo de produção da vida humana e dos demais seres vivos, por todo o mundo (CSDH, 2008).

Nessa perspectiva, o meio ambiente corresponde ao conjunto de condições, leis, influências e interações de ordem física, química, biológica, social, cultural e urbanística que permite, abriga e rege a vida em todas as suas formas (Brasil, 2002). O conhecimento das relações entre saúde e meio ambiente, principalmente as atinentes a situações de risco à saúde humana, fundamentam a importância de contemplar esse tema nas ações da ESF (Radicchi; Lemos, 2009). Além disso, percebe-se a relevância do tema, tendo em vista que as questões que englobam a relação saúde e meio ambiente são onipresentes e, por isso, podem repercutir diretamente na saúde das populações. Portanto, destaca-se a importância da realização de estudos que abordem a temática, principalmente dentro do setor da saúde, uma vez que se almeja sua promoção (Jing et al., 2016).

Na literatura, a relação saúde e meio ambiente vem sendo discutida por meio das relações existentes entre exposição e agravos à saúde, por exemplo: a poluição atmosférica e a associação com problemas respiratórios, doenças diarreicas e o saneamento básico, absorção de metais pesados e os agravos na saúde e, ainda, exposição aos agrotóxicos e efeitos na saúde (Cepeda et al., 2017; Graham; Polizzotto, 2013; Sankoh et al., 2016). Contudo, estudos que possuem essa temática, dentro do contexto da ESF, são escassos. Porém, podem configurar em subsídio para a ampliação do debate sobre o tema e reconhecimento da inserção da relação saúde e meio ambiente no âmbito dos serviços de saúde, em especial na APS.

Diante dessas afirmativas, formulou-se a seguinte questão de pesquisa: como a saúde e meio ambiente estão constituídos na representação social das equipes de ESF? O objetivo deste estudo, portanto, consiste em conhecer as representações sociais sobre saúde e meio ambiente para equipes de ESF.

\section{Método}

Trata-se de uma pesquisa de abordagem qualitativa, do tipo descritivo-exploratória, baseada na teoria das representações sociais (RS). A abordagem qualitativa busca reconhecer a história, as relações, as crenças, as percepções, ou seja, é o estudo das interpretações que as pessoas fazem a respeito de como vivem (Minayo, 2014). Já as RS compõem um sistema de classificação e denotação onde cada objeto ou ser possui um determinado lugar em uma clara escala hierárquica.

A RS forma-se a partir de dois processos: ancoragem e objetivação (Moscovici, 2013). No primeiro processo, existe uma aproximação com os novos conhecimentos ou objetos, no intuito de classificá-los e torná-los mais próximos aos indivíduos. Deste modo, forma-se o núcleo central da RS, determinando-se a significação e organização da representação (Morera et al., 2015, Moscovici, 2013). Já no segundo processo, a objetivação, formam-se os elementos periféricos. Estes circundam o núcleo central da RS e podem ser alterados por determinados contextos nos quais os indivíduos estão inseridos (Fonseca, 2016; Moscovici, 2013; Sá, 1996). Assim, as RS compreendem informações retidas, selecionadas e interpretadas com relação ao objeto e seu entorno, por isso têm papel importante na concretização do significado da representação, pois é por meio destes significados que a RS é externalizada (Morera et al., 2015; Moscovici, 2013). Perante esse processo de formação de RS, entende-se que a utilização da abordagem qualitativa, aliada à RS, permite acessar os significados que os participantes atribuem a um objeto (Rodrigues; Motta; Ferreira, 2013). 
Esta pesquisa foi desenvolvida em um município localizado no interior do estado do Rio Grande do Sul, que possui uma população de 6.347 habitantes, com Índice de Desenvolvimento Humano igual a o,744, e cobertura total de atendimento da população por ESF, com três equipes (Brasil, 2012; PNUD, 2013). Os dados foram coletados no período de fevereiro a junho de 2016, nas três equipes de ESF do município.

Foram elencadas duas técnicas de coleta de dados: pesquisa documental e entrevistas semiestruturadas. A primeira foi realizada em fontes primárias, ou seja, em documentos como: livros atas, fôlderes e outros registros de interesse para a pesquisa analisados entre os anos de 2006 e 2016. Essa delimitação temporal para análise dos documentos justifica-se em virtude de que o ano de implantação da primeira ESF no município foi 2006. Nessa etapa, realizou-se a busca por ações realizadas pela ESF que contemplassem a relação saúde e meio ambiente. A entrevista semiestruturada foi realizada com os profissionais de saúde atuantes nas três equipes de ESF do município.

Participaram desta pesquisa 19 trabalhadores que atuam junto das equipes de ESF nas seguintes funções e número de participantes: agentes comunitários de saúde (ACS) (10), auxiliar de saúde bucal (1), enfermeiros (2), médico (1), técnicos de enfermagem (3), e cirurgiões-dentistas (2). Estes foram convidados a integrarem a pesquisa, por meio de sorteio eletrônico em planilha de dados, tendo como critério de inclusão serem trabalhadores que atuem na ESF por, pelo menos, seis meses. Foram excluídos os participantes que estivessem em licença ou afastamento por qualquer motivo, durante o período de coleta de dados. Os participantes somente foram entrevistados após leitura, concordância e assinatura do Termo de Consentimento Livre, sendo que a pesquisadora ficou em posse de uma via deste documento, e a outra via com os participantes. Além disso, os participantes foram informados que poderiam interromper sua participação a qualquer momento.

Cabe ressaltar que todas as entrevistas foram realizadas em sala reservada e apresentaram tempo médio de duração de 45 minutos. Ademais, foram gravadas e transcritas na íntegra para posterior análise. Para o encerramento da coleta de dados, utilizou-se o critério de saturação dos dados (Fontanella et al., 2011).

Uma vez transcritos, os dados foram analisados com base no referencial proposto para análise de conteúdo na modalidade temática (Minayo, 2014). A partir disso, buscou-se o reconhecimento dos sentidos que viriam a constituir o núcleo central e a RS, por meio da abstração de significações presentes nas narrativas dos participantes. Os elementos periféricos foram também reconhecidos novamente por meio das narrativas, mas não assumiram a centralidade. Entretanto, emergiram no processo de análise de maneira complementar ao núcleo central desta RS. Assim, conforme propõe a teoria das RS, pode-se constatar que os elementos periféricos tendem a apresentar uma flexibilidade maior, quando comparados ao núcleo central da RS, haja vista que esses elementos podem sofrer alterações, dependendo do cenário em que o indivíduo está inserido e dos fatos ocorridos em determinado espaço de tempo. Após análise emergiu uma RS: a salubridade do território. Constituíram-se em elementos periféricos: a água, os resíduos sólidos urbanos, os agrotóxicos e a poluição atmosférica.

O projeto de pesquisa foi aprovado pelo Comitê de Ética em Pesquisa da instituição proponente, com parecer favorável sob o número 1.380.372 e Certificado de Apresentação para Apreciação Ética sob o número: 51719215.9.0ooo.5346. Os participantes tiveram sua identidade preservada, pois cada entrevista, ao ser transcrita, foi identificada com a letra 'P' de participante, seguida de números cardinais referentes à ordem de sua realização.

\section{Resultados}

\section{A salubridade do território: a representação social das equipes de ESF}

Como resultado do processo de análise de conteúdo emergiu o núcleo central, o qual foi formado a partir do processo de ancoragem da RS dos participantes do estudo. A figura o1 apresenta como a RS estruturada por meio dos processos de ancoragem, o qual corresponde ao processo de classificação para a formação do núcleo central da RS, e objetivação, que corresponde à forma de externalização da RS. 
Figura I - Estruturação da RS a partir dos processos de ancoragem e objetivação

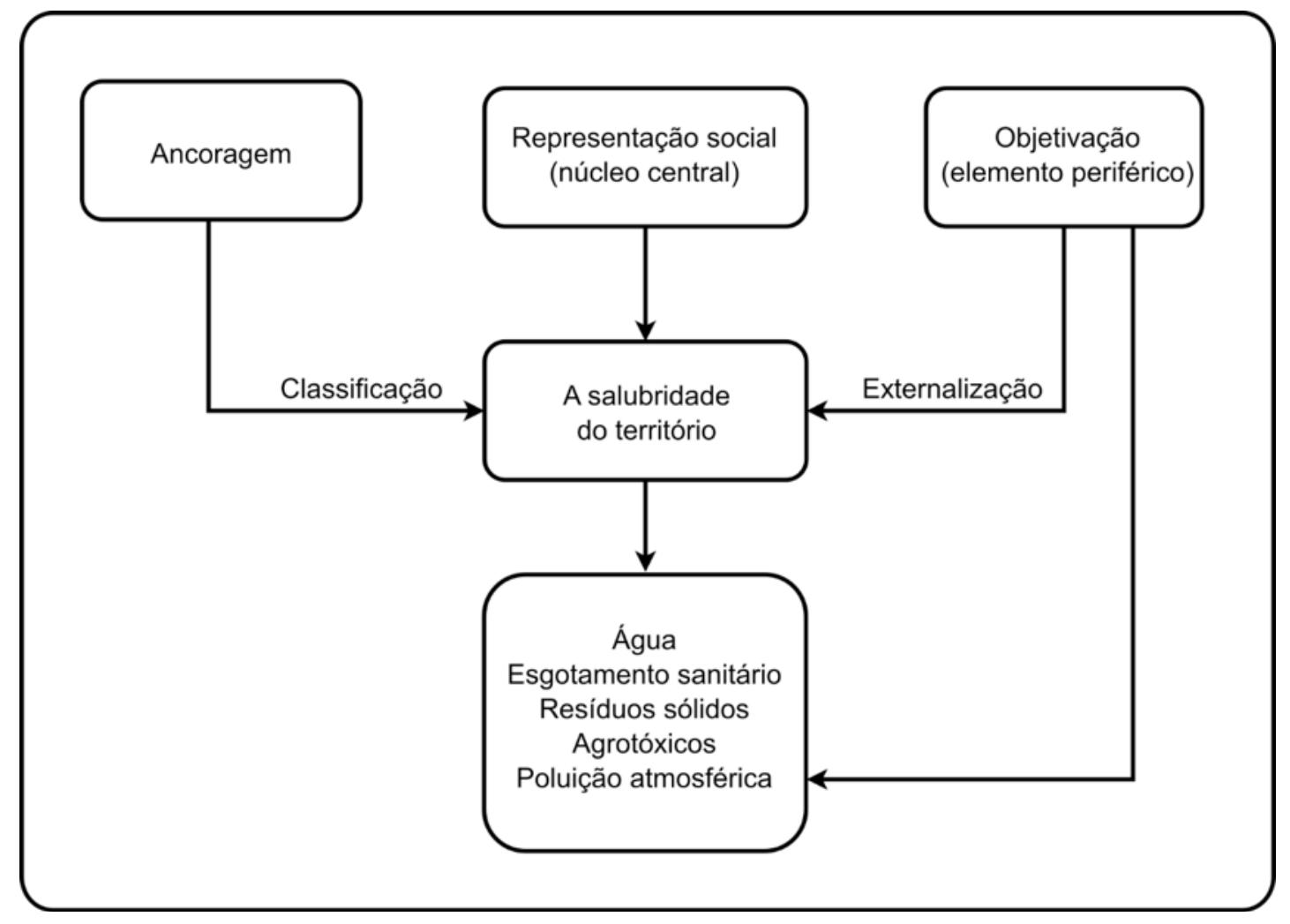

A RS que permeia o cotidiano dos participantes deste estudo é apresentada como "A salubridade do território", na qual a relação saúde e meio ambiente se faz presente por meio da identificação das alterações ambientais que influenciam o processo saúde e doença da população. Para mais, os elementos periféricos que fazem parte dessa representação reiteram esse núcleo de significados, pois externalizam a RS. Assim, a salubridade do território está relacionada com os seguintes elementos periféricos: água, resíduos sólidos urbanos, agrotóxicos e poluição atmosférica.

Nessa perspectiva, os participantes, ao refletirem sobre a relação saúde e meio ambiente, expressaram a RS voltada para aspectos sanitários e relacionam a saúde e o meio ambiente por meio da percepção do ambiente salubre.

Acho que uma coisa está relacionada com a outra. Porque tu tendo um ambiente saudável, meio ambiente saudável, tu tem uma saúde melhor. (P22)
Eu acho que incluitudo, relação das pessoas e o meio ambiente. Porque se tu tomar água contaminada, vaificar doente por causa disso, seria nesse sentido que eu penso. (P23)

Os relatos permitem compreender que a relação saúde e meio ambiente vincula-se ao meio ambiente saudável, sendo este considerado como precursor da saúde. Os participantes relacionam o surgimento de doenças com as alterações no meio ambiente, sendo que, no momento em que o meio ambiente se altera, a saúde é alterada também.

Eu acho que uma coisa está ligada com a outra [...]. No meu ver acho que uma depende da outra, se tu tem um meio ambiente bom, saudável, tu vai ter uma saúde boa. (P6)

Ainda nessa perspectiva, a salubridade do território se relaciona com o ambiente em que as pessoas vivem, podendo-se então inferir que, 
dependendo das condições desse ambiente, a saúde pode ser alterada.

Penso que se as pessoas não tiverem os cuidados básicos, as doenças aparecem. $\varepsilon$ os cuidados básicos estão bem ali. Onde elas vivem, no meio ambiente. (P11)

Assim, as questões relacionadas à saúde no sentido de que "o que poderia atrapalhar a saúde naquele meio?". No caso, de doenças, alguma coisa para as pessoas no geral. ( $\left.\mathrm{P}_{17}\right)$

Os depoimentos reforçam a ideia de que a salubridade do território influencia a saúde dos indivíduos inseridos nesses espaços. Somam-se a estes, os dados obtidos da pesquisa documental, os quais evidenciaram que diversas ações de cunho ambiental foram realizadas pelas equipes de ESF, de 2006 até 2016. Os documentos que demonstram esse fato foram os livros atas das três equipes, além de fôlderes elaborados pelos ACS. Nestes, os temas trabalhados foram a importância da qualidade da água, o descarte adequado dos resíduos sólidos e o uso de agrotóxicos.

Assim, de acordo com os participantes, a saúde e meio ambiente se relacionam por meio de uma associação de causa e efeito, dentro do território em saúde. Além disso, depreende-se que os participantes buscam materializar sua RS sobre saúde e meio ambiente por meio do desenvolvimento de ações dirigidas ao controle de variáveis ambientais e ações educativas, principalmente.

\section{Elementos periféricos da salubridade do território}

Os elementos que compõem o processo de objetivação são: água, resíduos sólidos, agrotóxicos e a poluição atmosférica. Esses elementos foram reconhecidos pela presença na RS, porém não são centrais nos discursos, eles aparecem de maneira periférica na RS e, por isso, tornaram-se complementares a ela. Destaca-se que a questão do esgotamento sanitário também foi mencionada pelos depoentes, compondo o processo de objetivação da RS, mas será objeto de discussão em outra publicação científica.

\section{Água}

No município onde se desenvolveu o estudo, a água é tratada como um recurso natural importante pelas equipes de ESF. De acordo com os registros, entre os anos de 2006 até 2012, os profissionais de saúde realizaram diversas atividades relacionadas com o tema água. Nesses registros, de forma geral, existia uma preocupação coletiva sobre o fornecimento de água para as populações do território. Além disso, é importante destacar que não só o abastecimento de água foi uma preocupação, mas a qualidade com que esse recurso natural chegava até a população. Ademais, as práticas desses profissionais transcenderam as equipes de ESF, pois foram realizadas ações intersetoriais com outros setores administrativos, como Empresa de Assistência Técnica e Extensão Rural (Emater), e o Setor de Vigilância Sanitária da Secretaria de Municipal de Saúde.

Nos anos seguintes, até meados de 2015 , as atividades relativas a esse recurso natural não foram realizadas. A partir do segundo semestre de 2015 os profissionais retomaram as atividades para sensibilização e controle da qualidade da água, organizando atividades de sensibilização com a população, o que está vinculado com a ocorrência de um surto de doenças de veiculação hídrica, no período. Essas atividades tinham por objetivo estimular hábitos de higiene na manipulação de alimentos, bem como o consumo de água tratada, seja pelo processo de cloração por pastilhas ou pelo método de fervura da água, como manifesto a seguir:

Tem muitos casos de diarreia, no verão principalmente, aíos agentes [agentes comunitários de saúde] vão lá, para detectar realmente se é por causa da água, se é por causa do alimento. ( $\left.P_{15}\right)$

Os participantes parecem sensibilizados quando o tema é água, pois diversas iniciativas foram organizadas com o intuito de melhorar a qualidade desse recurso natural, existindo, ainda, a preocupação com sua ausência. Ademais, os participantes relacionam o adoecimento da população com a contaminação desse recuso, conforme o depoimento a seguir: 
Daqui um tempo não vai ter mais água para beber, da poluição [...]. Mais ainda, as pessoas quevão láe fazem as necessidades Ireferindo-se a eliminações fisiológicas], e issovai para a água que elas tomam. Depois vêm as doenças como diarreias, vômitos. (P12)

Aí dá diarreia, tu trabalha, explica [...], algumas famílias mudam, outras que não conseguem [referindo-se às mudanças de hábitos] [...]. Porque dizem: "a minha vida inteira eu tomei dessa água, a minha vida inteira foi assim”, então é o que eles dizem. $\left(P_{3}\right)$

A partir dos relatos é possível reconhecer que o elemento periférico água faz parte do cotidiano das equipes de ESF, sendo capaz de alterar a saúde da população adscrita. Essas percepções sobre adoecimento relacionando causa e efeito, ou seja, alterações na qualidade da água e alterações na saúde vêm a reforçar a RS destas equipes.

\section{Os resíduos sólidos urbanos}

Para os participantes desta pesquisa, a geração e a destinação final dos resíduos são temas reconhecidos e compartilhados em diversos departamentos municipais. A pesquisa documental evidenciou que as ações que continham os temas resíduos sólidos urbanos (RSU), foram organizadas pelas Secretarias de Saúde, envolvendo os seguintes serviços municipais: Secretaria da Agricultura, Departamento de Infraestrutura e Obras. Contaram com o apoio de outras entidades ligadas a agricultura, como: a Emater e a Cooperativa Agrícola Mista instalada no município. Dessa maneira, foram organizados mutirões para coleta de resíduo em diversos espaços/territórios urbanos, organização da coleta na área rural e, ainda, atividades nas escolas e nas comunidades urbanas e rurais, com o enfoque para o descarte adequado dos resíduos.

Os participantes demonstraram preocupação com os impactos na saúde decorrentes do descarte inadequado de resíduos. Neste caso, relataram ações realizadas voltadas para essa questão, de acordo com os seguintes depoimentos:

Tem essas dificuldades de acesso, a questão do lixo, do saneamento que a gente vem trabalhando hámuito tempo com isso, porque não era visto como um problema de saúde também. Eu acho que aqui as pessoas têm o acesso, pelo menos. Mas assim, quando a gente trabalhou a gente fez muitas ações demutirão de lixo, porque chegava nas residências, $o$ lixo era jogado a céu aberto, não tinha nenhum tipo de recolhimento, nãofaz muito tempo que começouessa questão do recolhimento. $O$ destino era ali mesmo, até hoje tem bastante, a gente sabe que tem. (P8)

Agora até a gente comentando um pouco mais sobre a questão da dengue, a gente fez um mutirão, segunda-feira de tarde a gente juntoumuito entulho, muito lixo. A gente fez num rio que passa no fundo da comunidade lá, a gente juntou acho que uns 60 sacos de lixo. (P6)

Agora também, que a gente está trabalhando muito em cima da dengue. A gente vê certos pátios sujos. Que é um meio, assim, da gente cuidar também do meio ambiente que, às vezes, coisas, assim, tóxicas, que nem... a gente está trabalhando também, como lâmpadas, pilhas. ( $\left.P_{5}\right)$

Os depoimentos revelaram a apreensão dos participantes com a presença do vírus da dengue, retomando a discussão sobre a existência de depósitos irregulares de resíduos no município. Diante disso, percebe-se que existe preocupação por parte dos participantes em relação ao tema. Assim, como forma de resolução do problema de depósitos irregulares, os participantes citam o denominado mutirão de coleta de resíduos. Esse tipo de iniciativa é comum no município, de acordo com os achados relativos a esse elemento periférico.

\section{Agrotóxicos e poluição atmosférica}

O elemento periférico que compreende os agrotóxicos e a poluição atmosférica se faz presente, possivelmente em função de que o município em tela tem na agricultura sua fonte econômica principal. Nesse cenário, o uso de produtos e a poluição atmosférica fazem parte do cotidiano desses profissionais.

Mediante a pesquisa documental foi possível reconhecer que o tema "agrotóxicos" está sendo incorporado ao cotidiano dos participantes, por 
meio de um fôlder criado por eles e distribuíram para a população no mês de janeiro de 2016. Não foram encontrados registros do tema "poluição atmosférica”, embora os depoimentos direcionem para esse elemento periférico. Os depoimentos dos participantes a seguir evidenciam esta questão:

Quando é época de soja, assim, uma cultura que eles usam bastante agrotóxico, de tardezinha não dá para ti sair fora da porta da casa. Aquele cheiro, sabe, aquele ar que fica. Até esses dias eu tive que sair de casa e ir para a casa da minha irmã, porque eunão aguentava de dor de cabeça, eu sentio cheiro do veneno e começou a me dar dor de cabeça. $\varepsilon u$ fiquei um dia e pouco com dor de cabeça, eu vim um dia na reunião com dor de cabeça, só por causa do cheiro que eu tinha sentido. (P6)

A poluição, tuvai inspirar esse ar poluído, o que vai acontecer? Vai desencadear as rinites, as doenças respiratórias, que mais? Eu não sei se me preocupo mais porque eu tenho. Porque euvou para [referindose a determinada cidadel, para mim, eu ando no centro, lá parece que o ar é pesado. (P12)

De acordo com as narrativas, pode-se inferir que os participantes reconhecem a relação entre a poluição atmosférica - seja ela causada pelo uso dos agrotóxicos, ou ainda pela queima de matérias - e as repercussões nos estados de saúde dos indivíduos.

\section{Discussão}

Os relatos apontam que a relação saúde e meio ambiente está intimamente relacionada com a salubridade do território, pois, na medida em que se dispõe de um ambiente salubre, isso repercutirá na saúde da população. Dados de um estudo realizado com docentes de um curso de graduação em Enfermagem indicam que, na visão destes, a saúde e o meio ambiente possuem uma relação de causa e consequência, na qual o meio ambiente e os fatores ambientais vinculam-se à determinação de estados de saúde ou de doença (Camponogara et al., 2011). Ainda nessa perspectiva, a relação saúde e meio ambiente também foi reconhecida por enfermeiros de equipes de ESF como a ação do meio ambiente na saúde do ser humano (Santos; Silva; Azevedo, 2015).

Por muito tempo, a relação entre saúde e ambiente respondeu pela causa das doenças na compreensão miasmática. Nessa perspectiva, a doença era representada pelos miasmas presentes no ambiente (Junges; Barbiani, 2013). Entretanto, o avanço do conhecimento e da tecnologia no século XIX não só trouxe a descoberta de microrganismos e a teoria microbiana das doenças, mas a era em que a influência do meio ambiente sobre a vida humana tornou-se um ponto fundamental do pensamento científico e da consciência pública (Capra, 2014).

Esse evento mudou o pensamento científico e trouxe benefícios para a humanidade. Entretanto, carregou consigo um retrocesso na compreensão socioambiental da saúde, efeito que contamina, até hoje, a biomedicina, reduzindo o processo da saúde e da doença a fatores biológicos e epidemiológicos (Junges; Barbiani, 2013). Produziuse uma racionalidade para as intervenções da sociedade e do Estado, restringindo a dimensão social na determinação do processo saúde e doença e, assim, a sociedade vem sendo entendida como um agregado de indivíduos com características quantificáveis (Porto; Rocha; Finamore, 2014).

Atualmente, existe o reconhecimento de que as alterações ambientais como mudanças climáticas, usos de recursos naturais, formas de organização urbana, megaprojetos com impacto ambiental, medicamentos, agrotóxicos, entre outros, são questões de distintas escalas, que impactam os territórios de diferentes formas (Buss et al., 2012; CSDH, 2008). Depreende-se, então, que as novas doenças civilizacionais não têm uma origem somente microbiana, o que traz uma nova conotação ao aspecto ambiental. Com isso, o ambiente passa a ser representado como um ecossistema de interdependências naturais, sociais, políticas e culturais, que influenciam o processo saúde e doença (Junges, 2014). Sobre esses aspectos, aliado com o cotidiano dos profissionais das ESF, o trabalho desenvolvido em saúde é centrado no território e nas necessidades de saúde das famílias e comunidades (Dowbor; Westphal, 2013). Esse fato se relaciona com os elementos periféricos da RS dos participantes do estudo em tela, uma vez que água, os RSU, os 
agrotóxicos e a poluição atmosférica fazem parte do cotidiano desses profissionais e materializam-se nas ações por eles realizadas.

O elemento água, uma vez que faz parte do território dessas equipes, pode impactar no processo saúde e doença da população adscrita. Possivelmente esse fato possa justificar todo o trabalho realizado pelas equipes que foram descritos pela pesquisa documental, em prol da garantia do acesso e da qualidade da água. 0 reconhecimento desse elemento periférico na relação saúde e meio ambiente resgata a importância do que foi estabelecido na Conferência das Nações Unidas sobre Água em Mar Del Plata, na Argentina (Silva; Heller, 2016).

Naquela oportunidade, a água foi reconhecida como elemento fundamental para assegurar as necessidades básicas dos seres humanos (Silva; Heller, 2016). A percepção e a preocupação dos profissionais com o abastecimento e a qualidade desse recurso natural refletem o cenário mundial, pois esse tema vem sendo discutido como um dos determinantes à saúde, especialmente em países em desenvolvimento, tendo em vista que possuem uma rápida expansão urbana, adensamento populacional e ocupação desordenada de áreas periurbanas e rurais (Oliveira et al., 2015; WHO, 2011, 2016).

Em relação ao elemento periférico que abrange os RSU, os participantes demonstram-se preocupados com as atitudes da população, principalmente no que se refere ao descarte inadequado de RSU. Nesse sentido, como forma de redução dos impactos ambientais e de saúde pública, é necessário organizar um sistema de gerenciamento de RSU, conforme prevê a Política Nacional de Resíduos Sólidos (PNRS) (Brasil, 2010). Atualmente em vigor, a PNRS, estabeleceu uma série de diretrizes e ações para o gerenciamento de resíduos, destacando-se a logística reversa e a extinção dos denominados lixões ou aterros controlados (Brasil, 2010). Além da eliminação dos lixões e depósitos irregulares de resíduos, a PNRS prevê o sistema de logística reversa para resíduos que possuem alto grau de toxicidade, como: lâmpadas, pilhas, baterias, produtos eletrônicos e embalagens de agrotóxicos.

O gerenciamento inadequado de resíduos provoca danos diretos ao meio ambiente, como a contaminação do solo e da água. Os efeitos dessa contaminação repercutem diretamente na saúde da população, pois entre os componentes desses resíduos, encontram-se substâncias que são consideradas tóxicas a todos os modos de vida, tais como materiais que contêm os metais chumbo $(\mathrm{Pb})$ e mercúrio $(\mathrm{Hg})$. A intoxicação por chumbo ou mercúrio em humanos se relaciona com distúrbios no sistema nervoso central, bem como cardiovascular, no caso do chumbo (Cesar et al., 2011; Khoury et al., 2013). Além disso, estes metais podem ser dispersos no solo, na água e, ainda, contribuir para a poluição atmosférica (Bacila; Fischer; Kolicheski, 2014).

No que se refere ao elemento periférico dos agrotóxicos e poluição atmosférica, pode se perceber que se trata de um tema ainda novo no cotidiano dos participantes, tendo em vista que a pesquisa documental demonstrou que somente uma ação foi realizada. Nota-se, portanto, que os profissionais demonstram preocupação com os temas, embora estes se apresentem como novos. A compreensão do uso de agrotóxicos como um problema de saúde pública e ambiental vem crescendo em paralelo à disseminação de seu uso e na medida em que surgem novas evidências científicas sobre os impactos na saúde e no meio ambiente, decorrentes da utilização desses produtos (Carneiro et al., 2015; Ervilha, 2015).

Da mesma maneira, a falta de uso de equipamentos de proteção individual (EPI) pelo trabalhador rural é reconhecida como uma dificuldade a ser enfrentada pelos serviços de atenção à saúde. Entende-se que, pela rotina de trabalho, a qual comporta o manejo destes produtos, os agricultores estão mais vulneráveis para implicações na saúde em decorrência do contato direto com agrotóxicos (Carneiro et al., 2015). Um estudo com trabalhadores rurais da região central do estado do Rio Grande do Sul evidenciou que, dentre o total de trabalhadores rurais que utilizam os agrotóxicos em suas atividades agrícolas, 54\% não utilizam nenhum dos tipos de EPI (Silva et al., 2016). Além da contaminação dos trabalhadores, a pulverização, principalmente a realizada por avião, pode contaminar os alimentos, o solo, a água e o ar, tendo em vista que o agrotóxico pode ser carreado pelos ventos, promovendo a exposição de agricultores locais e de populações distantes do local de aplicação (Carneiro et al., 2015). 
Os participantes do estudo reconheceram a relação entre a exposição a poluentes e impactos na saúde da população. Diversos estudos evidenciam uma forte associação entre a contaminação atmosférica pelo material particulado e as internações por doenças respiratórias em crianças, bem como no desenvolvimento da asma. Outrossim, a exposição às substâncias referidas também foi associada ao número de nebulizações realizadas em determinada população (Carneseca; Achcar; Martinez, 2012).

Destaca-se que o fato de o estudo ter sido desenvolvido em um único município, pode se constituir em limitação da investigação. Além disso, o caráter exploratório, associado à escassez de estudos sobre o tema, utilizando esse referencial teórico-metodológico, também podem ser elencados como pontos limitadores da pesquisa.

\section{Conclusão}

Com a realização desta pesquisa, pôde-se conhecer como a relação saúde e meio ambiente se faz presente no cotidiano de trabalhadores de ESF. O objetivo do estudo foi atingido, na medida em que se conheceu que, para os participantes do estudo, a RS sobre o tema está relacionada à salubridade do território, a qual está ancorada nos seguintes elementos periféricos: água, RSU, agrotóxicos e poluição atmosférica.

A partir desta representação pode-se inferir que a compreensão da relação saúde e meio ambiente se constitui por meio dos danos que o meio ambiente pode causar na saúde, o que se materializa como uma relação de causa e efeito. Neste cenário, as práticas de saúde são voltadas, principalmente, para o manejo de questões ambientais que podem interferir na saúde da população e, algumas vezes, com ações educativas voltadas à população.

Sugere-se a realização de novas pesquisas sobre o tema, utilizando-se RS, no intuito de aportar conhecimentos científicos que possibilitem a obtenção de subsídios teóricos e práticos para os profissionais da saúde. Ademais, a realização dessa e de novas investigações oportunizam reflexões sobre a importância da promoção da saúde, a partir da valorização da relação saúde e meio ambiente, no âmbito da AP.

\section{Referências}

BACILA, D. M.; FISCHER, K.; KOLICHESKI, M. B. Estudo sobre reciclagem de lâmpadas fluorescentes. Engenharia Sanitária e Ambiental, Rio de Janeiro, v. 19, p. 21-30, 2014. Número especial.

BRASIL. Resolução no ${ }^{0}$ 306, de 5 de julho de 2002. Estabelece os requisitos mínimos e o termo de referência para realização de auditorias ambientais. Diário Oficial da União, Brasília, DF, 19 jul. 2002. Disponível em: <https://goo.gl/VUJkvT>. Acesso em: 24 jun. 2017.

BRASIL. Lei no 12.305, de 2 de agosto de 2010. Institui a Política Nacional de Resíduos Sólidos; altera a Lei ${ }^{0} 9.605$, de 12 de fevereiro de 1998 e dá outras providências. Diário Oficial da União, Brasília, DF, 3 ago. 2010. Disponível em: <https://goo.gl/tpFo>. Acesso em: 24 jun. 2017.

BRASIL. Ministério da Saúde. Departamento de Atenção Básica. Política Nacional de Atenção Básica. Brasília, DF, 2012. Disponível em: <http://189.28.128.100/dab/docs/publicacoes/ geral/pnab.pdf>. Acesso em: 26 jun. 2017.

BRASIL. Lei ${ }^{0} 12.864$, de 24 de setembro de 2013. Altera o caput do art. $3^{\circ}$ da Lei $n^{0} 8.080$, de 19 de setembro de 1990, incluindo a atividade física como fator determinante e condicionante da saúde. Diário Oficial da União, Brasília, DF, 24 set. 2013. Disponível em: 〈https://goo.gl/DJGpJp〉. Acesso em: 24 jun. 2017.

BUSS, P. M. et al. Governança em saúde e ambiente para o desenvolvimento sustentável. Ciência \& Saúde Coletiva, Rio de Janeiro, v. 17, n. 6, p. 1479-1491, 2012.

CAMPONOGARA, S. et al. A abordagem da interface saúde e meio ambiente na formação profissional de enfermeiros. Revista Gaúcha de Enfermagem, Porto Alegre, v. 32, n. 4, p. 647-653, 2011.

CAPRA, F. O ponto de mutação. São Paulo: Cultrix, 2014 .

CARNEIRO, F. F. et al. (Org.). Dossiê Abrasco: um alerta sobre os impactos dos agrotóxicos na saúde. Rio de Janeiro: EPSJV; São Paulo: Expressão Popular, 2015. 
CARNESECA, E. C.; ACHCAR, J. A.; MARTINEZ, E. Z. Association between particulate matter air pollution and monthly inhalation and nebulization procedures in Ribeirão Preto, São Paulo State, Brazil. Cadernos de Saúde Pública, Rio de Janeiro, v. 28, n. 8, p. 1591-1598, 2012.

CEPEDA, M. et al. Levels of ambient air pollution according to mode of transport: a systematic review. The Lancet Public Health. Amsterdam, v. 2, n. 1, p. 23-34, 2017.

CESAR, R. et al. Distribuição de mercúrio, cobre, chumbo, zinco e níquel em sedimentos de corrente da bacia do rio Piabanha, estado do Rio de Janeiro. Geochimica Brasiliensis, Rio de Janeiro, v. 25, n. 1, p. 35-45, 2011.

CSDH - COMMISSION ON SOCIAL DETERMINANTS OF HEALTH. Closing the gap in a generation: health equity through action on the social determinants of health. Geneva: World Health Organization, 2008.

DOWBOR, T. P.; WESTPHAL, M. F. Social determinants of health and the Brazilian family health care program in the city of São Paulo, Southeastern Brazil. Revista de Saúde Pública, São Paulo, v. 47, n. 4, p. 781-79o, 2013.

ERVILHA, I. C. Relatório: vigilância em saúde de populações expostas a agrotóxicos no estado do Rio Grande do Sul. Brasília, DF: Ministério da Saúde, 2015 .

FONSECA, C. V. A teoria das representações sociais e a pesquisa na área de educação em ciências: reflexões fundamentadas em produções brasileiras contemporâneas. \#Tear: Revista de Educação Ciência e Tecnologia, Canoas, v. 5, n. 1, p. 1-18, 2016.

FONTANELLA, B. J. B. et al. Amostragem em pesquisas qualitativas: proposta de procedimentos para constatar saturação teórica. Cadernos de Saúde Pública, Rio de Janeiro, v. 27, n. 2, p. 389-394, 2011.

FRUMKIN, H. Environmental health: from global to local. 3. ed. San Francisco: Jossey-Bass, 2016.

GRAHAM, J. P.; POLIZZOTTO, M. L. Pit latrines and their impacts on groundwater quality: a systematic review. Environmental Health Perspectives, Durham, v. 121 p. 521-530, 2013. JING, S. et al. Vulnerability assessment of urban ecosystems driven by water resources, human health and atmospheric environment. Journal of Hydrology, Amsterdam, v. 536, p. 457-47o, 2016.

JUNGES, J. R. Bioética e meio ambiente num contexto de América Latina. Revista Redbioética, La Rioja, v. 5, n. 9, p. 13-19, 2014.

JUNGES, J. R.; BARBIANI, R. Interfaces entre território, ambiente e saúde na atenção primária: uma leitura bioética. Revista Bioética, Brasília, DF, v. 21, n. 2, p. 207-217, 2013.

KHOURY, E. D. T. et al. Manifestações neurológicas em ribeirinhos de áreas expostas ao mercúrio na Amazônia brasileira. Cadernos de Saúde Pública, Rio de Janeiro, v. 29, n. 11, p. 2307-2318, 2013.

MINAYO, M. C. S. O desafio do conhecimento: pesquisa qualitativa em saúde. 14. ed. São Paulo: Hucitec, 2014.

MORERA, J. A. C. et al. Theoretical and methodological aspects of social representations. Texto \& Contexto Enfermagem, Florianópolis, v. 24, n. 4, p. 1157-1165, 2015.

MOSCOVICI, S. Representações sociais: investigações em psicologia social. 10. ed. Petrópolis: Vozes, 2013.

OLIVEIRA, L. B. et al. Gerenciamento comunitário de recursos hídricos, uma questão de saúde: a água que temos e a água que queremos: percepção dos usuários de sociedades de água em um município rural da sub-bacia hidrográfica do Forqueta, RS. Ambiência, Guarapuava, v. 11, n. 2, p. 359-374, 2015.

PNUD - PROGRAMA DAS NAÇÕES UNIDAS PARA O DESENVOLVIMENTO. O índice de desenvolvimento humano municipal brasileiro. Brasília, DF: Ipea, 2013. 96 p. (Série Atlas do Desenvolvimento Humano no Brasil 2013). PORTO, M. F. S.; ROCHA, D. F.; FINAMORE, R. Saúde coletiva, território e conflitos ambientais: bases para um enfoque socioambiental crítico. 
Ciência \& Saúde Coletiva, Rio de Janeiro, v. 19, n. 10, p. 4071-408o, 2014.

\section{RADICCHI, A. L. A.; LEMOS, A. F. Saúde}

ambiental. Belo Horizonte: Nescon: UFMG, 2009.

RANGEL, V. et al. Considerações para uma agenda estratégica de saúde e ambiente e sustentabilidade: horizontes da Fiocruz para 2022. In: BRASIL. Ministério da Saúde. Saúde e ambiente para as populações do campo, da floresta e das águas. Brasília, DF, 2015. p. 47-61.

RODRIGUES, I. L. A.; MOTTA, M. C. S.;

FERREIRA, M. A. Representações sociais de enfermeiros sobre o portador de tuberculose. Acta Paulista de Enfermagem, São Paulo, v. 26, n. 2, p. 172-178, 2013.

SÁ, C. P. Núcleo central das representações sociais. Petrópolis: Vozes, 1996.

SANKOH, A. I. et al. An assessment of the impacts of pesticide use on the environment and health of rice farmers in Sierra Leone. Environment International, Amsterdam, v. 94, p. 458-466, 2016.

SANTOS, D. A. S.; SILVA, M. S.; AZEVEDO, J. V. V. A saúde e o meio ambiente na visão do enfermeiro na atenção primária à saúde. InterfacEHS: Revista de Saúde, Meio Ambiente e Sustentabilidade, São Paulo, v. 10, n. 2, p. 95-107, 2015.

SHIMIZU, H. E.; REIS, L. S. As representações sociais dos trabalhadores sobre o Programa Saúde da Família. Ciência \& Saúde Coletiva, Rio de Janeiro, v. 16, n. 8, p. 3461-3468, 2011.

SILVA, A. C. et al. Socioeconomic profile of rural workers cancer sufferers. Revista de Pesquisa: Cuidado é Fundamental Online, Rio de Janeiro, v. 8, n. 3, p. 4891-4897, 2016.

SILVA, P. N.; HELLER, L. The right to water and sanitation as a tool for health promotion of vulnerable groups. Ciência \& Saúde Coletiva, Rio de Janeiro, v. 21, n. 6, p. 1861-1869, 2016.

WHO - WORLD HEALTH ORGANIZATION. Guidelines for drinking-water quality. 4. ed. Geneva: 2011. Disponível em: <https://goo.gl/ D83 Kdz>. Acesso em: 27 jun. 2017.

WHO - WORLD HEALTH ORGANIZATION. Preventing disease through healthy environments: a global assessment of the burden of disease from environmental risks. Geneva, 2016. Disponível em: 〈https://goo.gl/8mB3xC〉. Acesso em: 27 jun. 2017.

\section{Contribuição dos autores}

Dias, Camponogara e Costa participaram das etapas de concepção do estudo, análise e interpretação dos resultados. Todos os autores participaram das etapas elaboração da redação e revisão do conteúdo e aprovação final do manuscrito.

Recebido: 28/08/2017

Reapresentado: 14/12/2017

Aprovado: 29/12/2017 